\title{
Telephoning Fish: An Examination of the Creative Deviance Used by Wildlife Violators in the United States
}

EGAN K. GREEN

Associate Professor

Radford University

Department of Criminal Justice

307 Adams St.

Radford, Virginia 24142

Contact author - Egan K. Green: ekgreen@radford.edu; 0105408315995

\begin{abstract}
Wildlife poachers throughout the world have developed innovative techniques to commit their crimes and evade arrest by law enforcement. By taking advantage of technological advances as well as legitimate wildlife management practices, the poachers are able to participate in what Cohen and Machalek $(1988,1995)$ refer to as expropriative crime strategies. This paper documents specific non-conventional poaching techniques used as reported by 22 self-reported poachers, 14 wildlife law enforcement agents and 2 non-poaching hunters who were wildlife crime witnesses. The data, collected in semi-formal interviews, also present the different perceptions of poaching frequency and methods by both criminals and law enforcement officers.
\end{abstract}

Keywords: Wildlife Crime, Environmental Criminology, Rural-Specific Crime, Fish and Game Law, Wildlife Poaching 


\section{Introduction}

The relationship between intelligence and criminality has long been a source of debate among criminologists (Guay, Ouimet and Proulx 2005; McCarten and Gunnison 2004; Cullen, Gendreau, Jarjoura and Wright 1997; Hirschi and Hindelang 1977; Reiss and Rhodes 1961). Other cognitive characteristics such as impulsivity and level of self control have also been considered as possible explanations for criminal behavior (James and Seager 2006; Deffenbacher, Richards and Fitelli 2005; Gottfredson and Hirschi 1990). Yet, the creativity that goes into some types of crime has been largely overlooked by criminology. While "dumb crook" news garners media attention and chuckles from the public, occasional revelations of a previously unknown type of crime or method for committing crime may surprise those who hear of it. These acts of innovative deviance may not be highly complex, but they are new enough to make observers contemplate the creative thought processes undertaken by criminals. Cohen and Machelek's (1995) explanation of expropriative crime provides a theoretical understanding of this inventive deviance.

Wildlife crimes, such as illegal hunting and fishing, have been overlooked by criminological research. This bias is attributable to greater concern about urban crime, which influences crime policy. This article addresses this shortcoming by documenting several innovative methods of poaching undertaken by wildlife criminals. To understand how Cohen and Machalak's (1995) explanation applies to wildlife crime, it is necessary to discuss each.

\section{Expropriative Crime}

Cohen and Machalek $(1988,1995)$ address conventional as well as nonconventional actions by pointing out the expropriative nature of human behavior. They agree with Durkheim's assertion that crime is a normal part of social interactions. In accordance with this view and the observations of biologists, they note that the behavior of all organisms, human and animal, take on characteristics of expropriation. They define this expropriation as the process by which people take materials or services from others without regard to the victims. In quoting Wilson (as cited in Cohen and Machalek 1995) they note that when two organisms have interaction, one often procures benefits at the other's expense. When this usurption violates criminal laws, Cohen and Machalek refer to it as expropriative crime. However, to successfully complete the act, the person who is seeking to benefit from the interaction must have a strategy that will increase the likelihood of success. Hence, a criminal's strategy for performing a crime or to avoid apprehension has a great influence on his success. 
In relating this behavior to crime, it is important to remember that criminals operate in a world of other criminals. There is a threat therefore that the resources they seek are either protected by the lawful owners and/or guardians or threatened by other criminals. A successful criminal must be able to overcome legitimate obstacles to success as well as compete with others who wish to usurp the desired objects or services. Cohen and Machalek (1995: 157) state, “...likely outcome or payoff derived from an act depends greatly on the particular strategy or combination of strategies selected by an individual and on how effective it is against the other strategies utilized by his or her competitors."

Criminals and law enforcement agencies are in a type of escalating arms race. Each side alters its strategies to overcome the new challenges that are put in place to inhibit the success of the other. After the innovative criminals make their adjustments, law enforcement, material owners or service producers and other criminals are forced to react to the new innovative criminal strategies. Hence, the arms race escalates. Cohen and Machalek (1995: 160) describe this process:

"[T] he competitive ecological processes that give rise to expropriative crime over time frequently eventuate in defensive counter-reponses executed by producers and law enforcement agents aimed at the control and prevention of crime. Increasing or improving protective countermeasures by producers could thus limit payoffs and/or increase the costs of crime for expropriators. Such anticrime strategies could in turn (at least temporarily) serve to decrease the rates of specific types of crime within communities. However, such measures if effective, will serve also to encourage the development of new or modified illegal expropriative strategies by self-enhancing strategy innovators."

This escalation of tactics for successful criminal attempts is also noted by Paul Ekblom of the Centre for Research in Designing Out Crime and the University of the Arts, London (2000) who states, "Crime contends against crime prevention in a never ending arms race, with move and counter-move driven by accelerating technology and social change." Criminologist Marcus Felson (2006:149) also notes this arms races by stating, "...(W)e see that crime adaptability is not unidirectional. Rather, criminal and countercriminal activities are in perpetual contention, both engaging in trials and errors, having successes and failures."

People who perform expropriative behaviors take advantage of legitimately created or altered technologies in unintended ways to advance their strategies for success. For example, the internet provides many benefits to modern society. It facilitates easier distribution of information and, through email, and allows people to 
communicate in an inexpensive and simple to use format. However, people engaging in expropriative behaviors have taken advantage of the technology to inundate email inboxes with spam and some companies use software that installs spy ware on internet users' computers. The expropriators simply see an opportunity to gain some benefit at the expense of others when they view the helpful technology. It is not necessarily intelligence as much as a result of a lifestyle spent contemplating strategic methods of overcoming adversaries in pursuit of gain. Expropriative criminals are most likely to be innovative in their criminal endeavors.

Vila (1994) extends this theoretical explanation of criminal behavior as a general theory that integrates aspects of several other crime theories. His integrated developmental theory synthesizes macro and micro level factors with the influences of evolutionary ecology in human interactions to explain criminality. This creates a comprehensive explanation. For example, in referring to ecological factors that influence crime, Vila describes to the elements necessary for crime that are presented in Cohen and Felson's (1979) Routine Activities theory. Yet he points out, in accordance with Cohen and Machalek $(1988,1995)$, that specific behaviors result from typical socialization processes and that humans have social interaction tendencies which point them toward groups who reinforce behaviors.

In noting that humans are strategists, Vila (1994) points out that humans can develop and alter strategies that maximize benefits even without being aware of it. Furthermore, the pursuit of self benefit may utilize strategies with which the perpetrators are most psychologically comfortable. As he (Vila 1994: 323-324) states, "Internal psychodynamics also reinforce the development of strategic styles because people need to maintain some degree of consistency between self-image and behavior in order to avoid cognitive dissonance."

Further, Vila (1994) asserts that strategies and counterstrategies of criminals and guardians should be viewed as a vital link between research, practice and policy. Society has approached crime prevention with deterrence strategies (which try to reduce the criminal's motivation), protection or avoidance strategies (by incapacitating offenders), and nurturant strategies (which focus on childhood development). Yet the evolutionary nature of crime has continued as criminals alter their strategies to overcome anti-crime strategies. Vila (1994: 338) states, "(T)hese strategies need to be able to evolve quickly in response to changes in criminal strategies because of the potentially rapid nature of cultural evolution."

While using crime as a strategic approach to procurement of products or services may be a matter addressed by criminological theories that focus on socialization processes, it is the evolution of strategies that often create innovative deviance. As 
opportunities for crime are addressed by forces favorable to conventional behavior, an innovative offender who is still motivated to commit crime finds illegal methods to employ as a counterstrategy.

Crime trends have supported the ideas presented by expropriative crime. For example, Cohen and Felson (1979) point out that crime rates in the United States rose in the mid-1900s despite improving economic conditions. Much of this can be attributed to technological advances. As expensive items like electronics became smaller and more affordable, they became easier targets for motivated offenders. This same logic can be extended to what are now typical daily activities. When banks made electronic automated teller machines available for money acquisition 24 hours a day, robbers altered their strategies to wait for teller machine customers. The criminals can now adapt their approach to increase the likelihood of victimizing a person who is carrying money and has access to more. Furthermore, because this can be committed at night, fewer witnesses and guardians are available to apprehend the violator.

This paper explores how wildlife poachers use innovative strategies to commit their crimes and avoid detection. To understand this connection, it is necessary to review the relevant literature on wildlife criminals.

\section{Wildlife Criminals}

Due to criminology's bias toward urban crime, there is scant research on rural crime and few articles addressing wildlife crime. The small amount of research examining this type of deviance has revealed a number of intriguing findings concerning frequency and expropriative poaching. Poaching frequency must be considered because offenders can alter their strategies to avoid detection. As noted by Cohen and Machalek (1988, 1995), successful expropriative criminal behaviors

will minimize the odds of being arrested. Considering frequency of this deviance provides a picture of how successful innovative evasive behavior is.

Green (1990) interviewed convicted poachers in one of the northeastern states in the United States to test the validity of the polygraph machine. His participants claimed to have poached on several occasions prior to the event for which they were arrested. Green's research indicates that previous successful poaching events ranged from a few to fifty. One of Green's participants admitted to having poached deer once a week for two months out of every year for several years before he was arrested.

Farnsworth (1980) examined the black market of poached animals and animal parts by collecting data from every state game enforcement agency in the United 
States as well as the U.S. Fish and Wildlife Service. Additionally, he interviewed regional supervisors from two states' park services. Based on this data, Farnsworth (1980) estimated the minimum value of the international animal and animal parts market was over $\$ 175$ billion (US) in 1980. This made the international black market second only to the international drug market in terms of money exchanged. It is logical to assume that innovative techniques are necessary to avoid apprehension for all of this commercial poaching to occur.

In terms of innovative techniques of poaching, Halstead (1992) presents an interesting twist of the international market for illegal wildlife. In noting the challenges of illegally importing and exporting of fauna and flora in Australia, he points out that there are legal as well as illegal ways to traffic in animals and animal parts. Therefore traffickers have opportunities to "launder" illegally imported animals into legal creatures by claiming that the animals were bred in non-indigenous regions. Exotic pet traffickers can therefore sell more than their legally accounted for number of animals and claim they are part of the legal offspring.

Halstead (1992) notes innovative strategies of wildlife poachers including illegally smuggling the eggs of birds or reptiles to other geographic areas that lack stringent wildlife laws and incubating them to hatch. The animals often return to where they hatched to lay their own eggs. Illegal wildlife traffickers therefore establish a renewing supply of illegal, non-indigenous animals with minimal cost after an initial smuggling operation.

A basic understanding of wildlife crimes also demonstrates support for the notion of expropriative crime. As poaching methods were countered by law enforcement strategies, poachers had to alter their tactics to continue their practices while still minimizing the likelihood of detection and apprehension. Furthermore, as pointed out earlier, as with other crimes, technological advances have helped facilitate the poachers' ability to commit their crimes and avoid law enforcement officials. For example, poachers were able to continue hunting illegally while becoming more mobile to avoid arrest by taking advantage of the mobility that automobiles provided. Perpetrators were able to drive through rural areas at night searching for deer to spotlight and shoot. They were then able to collect their game and leave the crime scene quickly. Wildlife law enforcement agencies developed counterstrategies to catch up to these tactics through technological advances in robotics. Mechanical deer which were movable through remote control devices were created and placed on roadsides at night. The game officers now keep watch from a nearby hidden location. They come forward and make an arrest when roadside poachers shoot at the robots. The evolution of these mechanical animals eventually expanded to other animals because game enforcement agencies needed to counter the poachers' move toward 
poaching different animals. The counter strategies of the poachers are the focus of this paper.

\section{Methodology}

In carrying out other research pertaining to wildlife crime, the researcher came upon stories of poachers who bragged about the innovative methods of poaching that they had used. This project documents and catalogs these methods in an attempt to achieve a better understanding of this type of crime and develop policies that counteract the poachers' strategies.

A series of semi-formal qualitative interviews were carried out with admitted poachers, wildlife enforcement agents and self proclaimed witnesses to wildlife crimes in the United States. Because this research is exploratory and the particular poaching actions had not yet been listed in previous research, the qualitative approach was appropriate (Maxfield and Babbie 2005; Maxwell 1996). Initial contacts were made through previous acquaintances of the researcher. Some of these participants had participated in previous research projects so the researcher had already been privy to poaching "war stories." Other contacts were made through the snowball method of sampling discussed by Maxfield and Babbie (2005). This sampling method starts with contacts who have knowledge helpful to a researcher. Those contacts provide information for contacting other people who can provide further information. The final sample included 22 self reported wildlife violators, 14 wildlife law enforcement officers and 2 legitimate hunters who had witnessed expropriative poaching techniques.

The interviews included questions about exposure to and knowledge of innovative methods of poaching. For this project, wildlife poaching is defined as the illegal killing, taking or capturing of fauna and flora. Furthermore, the study participants were asked about tactics for avoiding detection or apprehension by law enforcement. It is posited here that these tactics are the expropriative strategies used by this population of offenders.

\section{Interview findings}

When asked to discuss any unique methods of poaching that poachers have used, the participants reported some unsurprising methods such as shooting deer from roadways and using nets to catch fish. However, innovative methods were also reported. As expected, these methods often take advantage of technology. For example, one poacher admitted to using night vision equipment to track and shoot animals at night. A different participant admitted to using a silencer and two discussed their use of dynamite in bodies of water to kill fish. When asked about 
innovative methods of poaching to which he had been exposed, one wildlife officer said, "Every method of poaching is unique. I am forever amazed at the thought and time that some people will invest into taking game illegally. Just when you think you have seen it all, you haven't."

\section{Telephoning Fish}

Telephoning fish is actually a method of electrocuting fish until they are stunned to the point that they rise to the surface of the water. This is typically done with an earlier model telephone that requires a user to crank a handle which turns a generator to build a charge. Poachers place the wires that transmit the charge into small bodies of water and turn the crank generating enough electrical charge to stun the nearby fish. The creatures float to the surface of the water and the poacher simply retrieves them.

Two poachers in this study's sample admit to having performed this act, and three others report knowledge of other poachers performing some variation of this crime. Four law enforcement officers also reported coming across variations of this poaching method in the course of their work. The variations include shocking fish with battery packs or even small generators. In referring to this method one officer stated, "This produces a large enough jolt to kill the fish. It is typically done for catfish and is now even being done off of batteries that the poacher hides in his gear."

The following are examples of the statements the participants made in referring to this poaching method when asked about innovative tactics.

Use telephones to shock fish. This is so poachers can float fish to the top and scoop them up with a net.

Using an old crank phone to crank up fish.

Shocking the fish. Electrifying the water. Causing the fish to become temporarily paralyzed."

I would have to say the use of small electronic devices to stun fish instead of the old method of using the crank phones.

A disturbing consideration is the fact that variations of this poaching method are used as legitimate wildlife management techniques. Wildlife biologists use portable generators to stun fish so they can be collected for management techniques like counting and marking fish. This implies that poachers acquire some of the knowledge for poaching from legitimate sources. This is discussed in more detail in a later section of this paper. 


\section{Rocket Nets}

A strategy for illegally capturing waterfowl is also a legitimately accepted wildlife management technique that has come to be known to poachers. Rocket netting requires the use of a large net, any of a number of forms of staking methods and model rockets. This poaching strategy is often combined with baiting. The net is laid flat and camouflaged. One side of the net is staked down, or weighted down in shallow water. The net is also staked or weighed down at the point approximately halfway to the other side of the net. The remaining free side of the net is also laid flat, but the end corners and middle section are attached to model rockets which are designed to shoot into the air. Bait is placed on the staked half of the flat net and the poacher waits at the rocket end of the net. When the prey, typically fowl, are on the net to partake of the bait, the poacher fires the rockets which propel upwards. Because the models are fettered at the halfway point of the net, they are pulled downward and toward the far end of the net. The net therefore flies over the prey, pulls taunt, and flies back down. In doing so it pins the birds under the net.

An officer reporting this poaching technique stated that it can catch thirty to forty turkeys in one successful use. This method of catching prey is documented as a legitimate manner to catch birds for wildlife census and other management needs (Heath and Frederick 2003; Cox and Afton 1994; Grand and Fondell 1994). This method can be combined with decoys or baiting to increase the catch.

\section{Remote Control Aircraft}

A poacher and a wildlife officer in this sample each described the use of remote controlled model airplanes to steer waterfowl to the poacher's location. The tactic involves finding a waterborne location suitable for a duck blind that is close enough to a strip of firm ground that is long enough for the plane to take off and remain within remote control range of the blind. Once in position to poach, the perpetrators listen and watch for flying gaggles of waterfowl. The model plane is launched and then controlled in such a way that it harasses the birds and steers them in the direction of the poacher. Once within firing range, the poachers unleash their shots on the fowl.

The following are quotes from the participants who discussed this innovative poaching method.

$(U)$ sing the radio control crafts brings in everyone's limit plus some.

It is an inventive way to poach, but it is illegal. 


\section{Running Gun}

This poaching method is carried out in a variety of ways, but the basic idea is to run upon an animal and shoot it at short range. One participant describes the method by claiming to have one person go into the forest to seek out an animal. Once one is aroused and running, this runner radios the direction he is running the game to his poaching partner. The partner sets an ambush ahead of the game and jumps out to shoot at it. Problems that arise include the poacher not getting ahead of the animal and having to chase it and shoot it during the chase. The original animal runner must also be careful to avoid being shot.

A variation of this method described by a non-poaching witness involves the poachers hiding behind cows in pastures where deer frequent. As night approaches the deer exit the forest and mingle with the cows. The poachers, hiding behind cows, work their way close to the deer and shoot them at short range, usually in the head, with pistols. This lower caliber weapon creates a smaller sound report and is less likely to draw unwanted attention.

To avoid detection in removing the deer from the area, the poachers carried portable tanks of compressed air. They insert a hose into the deer's rectum and inflate them with air then ease them into the nearest river. A partner in a pickup truck waits downstream in a sparsely populated area for radio or cell phone notification and keeps watch for the floating deer. This accomplice hooks the deer from the stream, loads them into his covered truck bed and then picks up his partners at a prearranged location.

One of the participating wildlife enforcement officers stated that a similar tactic had been used by duck poachers. The criminals would duck hunt near a river. They shot more than their legal limit of ducks. They kept the legal number that they were allowed and drifted the rest downstream to a waiting friend who picks them up and meets them later.

\section{Ground Buckeye Leaves}

Three poachers admitted to using natural products to illegally harvest fish. The leaves of the North American Buckeye tree and walnut hulls are used stun the prey in this method of poaching. One poacher admitted to using buckeye leaves, another uses walnuts, and a third uses both. The buckeye poacher stated, "I'll use ground up red buckeye leaves to stun the fish. Some chemical in them stuns the fish which brings them to the surface. I just go collect them." 
Another poacher describes the method this way, "You know walnuts have all that dark stuff. If you put a bunch of walnuts in a sack after you smash them up and then put it in a stream, it will take the oxygen out of the water. But it only works a little way downstream. It couldn't work in a pond because it's too much water. By taking out the oxygen it makes the fish immediately downstream float to the top. If there was enough it could kill them, but usually it just knocks them out."

This poaching tactic has apparently been passed down through folk tradition. This method of catching fish was used prior to technology like the phone. The United States Department of Agriculture states that Native Americans used to ground buckeye leaves into powder to be released in a stream to stun fish (available online at http://plants.usda.gov/plantguide/pdf/pg_aegl.pdf).

\section{Baiting}

Baiting is the most common type of poaching according to this sample. The conservation officers as well as the poachers refer to it as the type of poaching that produces the most game in the shortest time, and more so than any other method. While this is not particularly original, the variations on this poaching method demonstrate innovative strategies.

One wildlife officer pointed out a particularly cruel method of baiting which he discovered. When asked about innovative poaching methods, he stated, "I have ran [sic] into one case that I found a man poaching turkeys. His way of doing so was with trot lines hanging from trees in the woods. He would put corn on the hooks and would check the lines periodically."

The turkey would go for the corn on the trot lines' fish hooks. Once they began, they would be hooked in the mouth or throat by the hooks and hang from the lines slowly dying. A different poacher admitted to using this method to hang meat from a small game animal like a rabbit to attract coyotes. He would return to the baited area around dark and shoot the coyotes that were hanging by the bait.

Another baiting variation is reported by another officer. When he was asked about innovative poaching methods which he has discovered he stated, "Yes, they bait up a bunch of ducks and geese and use claymore mines to shoot them."

Claymore mines are military, anti-personnel mines. They are manually operated and fire a spray of small metal balls to create shrapnel to kill targets close to the front of the blast. This creates the opportunity for a large kill of the waterfowl. 
One poacher admitted to using bait to attract game to a covered net that tangles up the wildlife until he could come in for the kill. This same poacher also claimed to dig large pits in the forest, covering them with tarps and baiting the area. Obviously the prey goes for the bait on the tarp and falls into the pit where he is easily targeted to be killed or captured.

\section{Tightrope Bridge}

An officer in the sample stated his surprise at a poacher's use of a rope that had been stretched from a lake shore to a water-locked lake island. Knowing that using a boat to travel to the island for his poaching would be more likely to attract unwanted attention, the poacher had strung a long rope from a hidden location on the land shore. The rope was buried to the location where it was underwater. The poacher was then able to swim and cling to the rope. The rope was also important because it would facilitate the transport of his prey from the island back to shore. After dark, the poacher would tie his prey to the island end of the bridge and could pull it back to the lake shore.

\section{False Compartments}

Part of the expropriative nature of crimes includes avoiding detection. Poachers created false compartments in vehicles. These compartments were used to hide the animals that had been killed. One wildlife enforcement officer came upon a truck that had been modified to have hidden compartments behind the truck seat, under the truck bed, in the hubcaps and under the hood. He said the compartments were mostly used for hiding small game like ducks or squirrels. A poacher in the sample also discussed using hidden compartments in vehicles for hiding small game that had been killed. However, the wildlife enforcement officer discussing this technique stated that during the course of one of his investigations, he had come across a compartment that had been built on the bed of a truck that was big enough for a deer carcass. The compartment would then be hidden with bails of hay or other "junk" that would be piled on top of it to conceal its existence.

\section{Hide and Return}

Three wildlife officers and a poacher in the sample pointed out the use of global positioning technology to hide killed game or gill nets. The strategy allows poachers to kill an animal and hide it in a secluded location. The poachers save the exact location as a waypoint on handheld global positioning units. This lets poachers stretch their territories for poaching into locations that may be unfamiliar to them. They can then leave the location without the killed game and go back to retrieve it at 
a time when detection is less likely or from a direction less frequented by witnesses or guardians.

Fish poachers use this technology by dropping nets into bodies of water to catch or hide caught fish. Because landmarks are sometimes sparse in large bodies of water, the fish poachers will mark their location as a waypoint and come to retrieve their game at a safer time. In a variation of this, one game warden stated that he had discovered duck poachers hiding illegally killed ducks in a custom made fiberglass box that was sunk into deep mud. They would mark the location and return to retrieve the box later.

\section{Discussion}

Cohen and Machalak's $(1988,1995)$ explanation of crime is important for understanding how crime evolves in society. The data provided from these interviews points out the evolution of wildlife poachers. The unique poaching strategies explained in this study demonstrate expropriative characteristics because of their innovations designed to increase success while simultaneously minimizing risk of detection. Furthermore, many of the techniques revolve around increasing the number of animal victims of their crimes. Due to the size of the group of fish or game caught or killed, these techniques should be helpful for dealing with commercial poaching. For example, fowl poachers may use techniques like rocket netting to capture several birds. Cox and Afton (1994) point out that this bird capturing method produces low mortality rates. Therefore, live capture is probable with rocket netting. These birds may then be smuggled to non-indigenous regions to reproduce in accordance with the strategies discussed by Halstead (1992). Noncommercial poachers are less likely to have a need for dozens or hundreds of illegally collected birds at a time, particularly if they are still alive.

The use or alteration of established wildlife management techniques is an additional concern stemming from this research. For example, rocket netting is an established method for biologists to capture waterfowl (Cox and Afton 1994). The method has also been used to capture non-migratory waterfowl such as turkeys, grouse and bald eagles. Grand and Fondell (1994) also used this method using decoys to capture pintails in Alaska. Heath and Frederick (2003) used rocket and mist nets in the Everglades to trap White Ibises.

Using electricity to stun fish so they can be collected is another established method of wildlife management (Nielsen 1998; Jowett and Richardson 1994; Barrett and Grossman 1988; Moore, Larson and Ridley 1986). Biologists use portable generators that are either handheld or strapped on their backs. The same principle 
that the poachers employ is applied, but biologists use generators which are specifically designed for stunning fish.

It is clear that just as Cohen and Machalek $(1988,1995)$ discuss, legitimately used technologies are expropriated for illegitimate purposes. What is more disturbing is the possibility that people who have been educated on these legitimate management techniques are the expropriators. It is possible wildlife management employees or students are using these techniques or passing knowledge of them on to acquaintances who are poachers.

It is clear that technology is playing a role in many of the expropriative behaviors demonstrated by the poachers. The use of global positioning equipment, firearm silencers, night-vision scopes, military mines and two-way radios were discussed by participants as useful tools for easing their criminal behaviors. These methods are helpful for capturing or killing their game as well as avoiding detection. It is clear from this data that poachers have been employing expropriative strategies in their criminal endeavors.

\section{Conclusions}

The power of Cohen and Machelek's $(1988,1995)$ theory in explaining poaching takes into account the competition for resources. Poaching is a unique crime because there are legal alternatives. People can hunt or fish under legal circumstances; they only need to purchase a license and follow the prescribed rules for most species. This is not true of many other crimes. It is always illegal to sell or purchase certain drugs in most countries. So the logical question arises as to why poachers would elect to break the law to accomplish the same goal. Because the poachers see themselves in competition for resources (fish and game), they must come up with innovative techniques to maximize their gain while still minimizing their risk. Poachers are in competition with law enforcement, other poachers and legitimate hunters who are also reducing the number of accessible plants and animals.

Vila's (1994) extension of Cohen and Machalak's theory provides a clear link between research on this theory and policy. By developing counterstrategies to crime that take into account the criminal counterstrategy, criminal acts can be prevented. The important aspect of this is that guardians stay two steps ahead in the arms race. Furthermore, the offender must be aware of the two step advance prior to committing the crime or the counterstrategy becomes an attempt at apprehension as opposed to deterrence. 


\section{References}

Barrett, J.C. \& Grossman, G.D. 1988. Effects of direct current electro-fishing on the mottled sculpin. North American Journal of Fisheries Management, 8, 112116.

Cohen, L.E. and Felson, M. 1979. Social change and crime rate trends: A routine activity approach'. American Sociological Review, 44, 588-608.

Cohen, L.E. \& Machalek, R.S. 1988. A general theory of expropriative crime: An evolutionary ecological approach. The American Journal of Sociology, 9, 465-501.

Cohen, L.E. \& Machalek, R.S. 1995. Behavioral strategy: A neglected element in criminological theory and crime policy. Pp. 157-178 in H.D. Barlow (Ed.), Crime and public policy: Putting theory to work. Boulder, CO: Westview Press, Inc.

Cox, Jr., R.R. \& Afton, A.D. 1994. Portable platforms for setting rocket nets in openwater habitats. Journal of Field Ornithology, 65, 551-555.

Cullen, F.T., Gendreau, P., Jarjoura, G.R. \& Wright, J.P. 1997. Crime and the bell curve: Lessons from intelligent criminology. Crime and Delinquency, 43, 387-411.

Deffenbacher, J.L., Richards, T.L. and Filetti, L.B. 2005. Angry drivers: A test of state-trait theory. Violence and Victims, 20, 455-469.

Ekblom, P. 2000. Future crime prevention - a 'mindset kit' for the seriously foresighted. Online: http://www.foresight.gov.uk/Crime\%20Prevention/Futire_Crime_Prevention Mindset_Kit_March_2000.pdf (accessed July 2, 2008).

Farnsworth, C.L. 1980. A descriptive analysis of the extent of commercial poaching in the United States. Unpublished doctoral dissertation, Sam Houston State University, Huntsville, Texas.

Felson, M. 2006. Crime and Nature. Thousand Oaks, CA: Sage Publications.

Gottfredson, M. \& Hirschi, T. 1990. A General Theory of Crime. Stanford, CA: Stanford University Press. 
Grand, J.B. \& Fondell, T.F. 1994. Decoy trapping and rocket-netting for northern pintails in spring. Journal of Field Ornithology, 65, 402-405.

Green, G.S. 1990. Resurrecting polygraph validation of self-reported crime data: A note on research method and ethics using the deer poacher. Deviant Behavior, $11,131-137$.

Guay, J.P., Ouimet, M. \& Proulx, J. 2005. On intelligence and crime: A comparison of incarcerated sex offenders and serious non-sexual violent offenders. International Journal of Law and Psychiatry, 28, 405-417.

Halstead, B. 1992. Traffic in flora and fauna. Australian Institute of Criminology Trends and Issues in Crime and Criminal Justice, 41, 1-9.

Heath, J.A. \& Frederick, P.C. 2003. Trapping white ibises with rocket nets and mist nets in the Florida Everglades. 74, 187-192.

Hirschi, T. \& Hindelang, M.J. 1977. Intelligence and delinquency: A revisionist review. American Sociological Review, 42, 571-586.

James, M. \& Seagar, J.A. 2006. Impulsivity and schemas for a hostile world: Postdictors of violent behavior. International Journal of Offender Therapy and Comparative Criminology, 50, 47-56.

Jowett, I.G. \& Richardson, J. 1994. Comparison of habitat use by fish in normal and flooded river conditions. New Zealand Journal of Marine and Freshwater Research, 28, 409-416.

Maxfield, M.G. \& Babbie, E. 2005. Research Methods for Criminal Justice and Criminology. ( $4^{\text {th }}$ Ed.). Belmont, CA: Wadsworth Thomson Learning.

Maxwell, J.A. 1996. Qualitative research design: An integrative approach. Thousand Oaks, CA: Sage Publications.

McCarten, L. \& Gunnison, E. 2004. The IQ/intelligence relationship: An extension and replication of previous research. Journal of Crime and Justice, 27: 61-86.

Moore, S.E., Larson, G.L. \& Ridley, B. 1986. Population control of exotic rainbow trout in streams of a natural area park. Environmental Management, 10, 215219.

Nielsen, J.L. 1998. Electrofishing California's endangered fish population. Fisheries, $23,6-12$. 
International Journal of Rural Criminology, Volume 1, Issue 1 (December), 2011

Reiss, A.J. \& Rhodes, A.L. 1961. The distribution of juvenile delinquency in the social class structure. American Sociological Review, 26, 720-732.

United States Department of Agriculture. n.d. Plant guide: Ohio buckeye. Online. Retrieved November 8, 2006, from http://plants.usda.gov/plantguide/pdf/pg_aegl.pdf

Vila, B. 1994. A general paradigm for understanding criminal behavior: Extending evolutionary ecological theory. Criminology, 32, 311-359. 